\title{
¿SON ABSOLUTOS LOS DERECHOS HUMÁNOS? EL DESAFÍO DE LOS PRINCIPIOS INSTITUCIONALES
}

\author{
Ángeles Ródenas \\ Universidad de Alicante
}

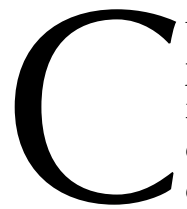

uando estaba terminando la licenciatura llegó a mis manos — seguramente por recomendación de Manuel ATIENZA o de Juan Ruiz MANERo, ya no recuerdo bien - un artículo de un tal F. LAPORTA titulado «Sobre el concepto de derechos humanos» ${ }^{1}$. Si soy sincera, al principio no entendí gran cosa del mismo pero, como tengo un carácter empecinado, volví a releerlo una y otra vez hasta adquirir una comprensión aceptable de los problemas abordados en el texto. Ese artículo, que tanto me costó inicialmente de comprender, ha sido, sin embargo, uno de los trabajos de filosofía del Derecho a los que más debo y que más decisivamente ha estructurado mi pensamiento cada vez que he tenido que plantearme la compleja cuestión de las relaciones justificativas en el Derecho. Es por ello, y por la feliz coincidencia de que Liborio HIERRO termina de publicar un libro sobre los derechos humanos ${ }^{2}$ - que estimo se va a convertir en un clásico sobre la materia — por lo que he escogido este aspecto de la obra de ambos autores para mi contribución a su homenaje.

Tomaré como punto de partida las reflexiones de LAPORTA respecto de uno de los rasgos que comúnmente se predican de los derechos humanos: su carácter absoluto. Seguidamente mostraré algunos casos paradigmáticos en los que asumimos que ciertos principios institucionales limitan justificadamente el ejercicio de derechos fundamentales, lo que me llevará a cuestionar la antedicha caracterización de los derechos humanos como derechos absolutos. Concluiré apuntando ciertas similitudes inquietantes entre alguna de las tesis que asumo en mi análisis y determinados postulados del comunitarismo y del consecuencialismo.

\section{PLANTEAMIENTO: EL CARÁCTER ABSOLUTO DE LOS DERECHOS HUMANOS}

De acuerdo con el análisis de LAPORTA ${ }^{3}$, cuando se afirma que los derechos humanos son absolutos, lo que se pretende subrayar es la idea de que constituyen una

${ }^{1}$ Cfr. F. LAPORTA, «Sobre el concepto de derechos humanos», Doxa. Cuadernos de filosofía del Derecho, núm. 4, 1987, 23-45.

2 Cfr. L. Hierro, Los derechos bumanos. Una concepción de la justicia, Marcial Pons, 2016.

3 Cfr. F. LAPORTA, op. cit., 36-42. 
exigencia moral particularmente fuerte. En concreto, los derechos humanos serían «enunciados morales incomparables con todos aquellos otros enunciados morales que no atribuyen derechos; es decir, que no pueden ser puestos en una balanza para ser contrapesados, y eventualmente desplazados, por consideraciones que no incorporen derechos, aunque sean considerados morales». Así pues, «los enunciados morales que describen y atribuyen derechos son requerimientos más fuertes que los demás enunciados morales y que, por tanto, en caso de conflicto, los desplazan necesariamente».

Siguiendo con el análisis de LAPORTA, que los derechos humanos sean concebidos como los requerimientos morales más fuertes que se dan en el discurso moral no significa que no puedan ser nunca desplazados: lo pueden ser por requerimientos morales equivalentes en conflicto con ellos, es decir, por otros derechos humanos. «Solo cuando nos encontramos frente a un conflicto de derechos humanos - señala LAPORTAcabe pensar en el desplazamiento justificado de uno de ellos en favor del otro». En suma, «se dice que los derechos humanos son absolutos porque en caso de conflicto con demandas morales colectivas o con demandas individuales no constitutivas de derechos, logran imponerse a ambas, desplazándolas» ${ }^{4}$.

\section{EL DESAFÍO DE LOS PRINCIPIOS INSTITUCIONALES}

A continuación me voy a plantear hasta qué punto esta caracterización de los derechos humanos como absolutos es compatible con la inclusión de razones institucionales en las deliberaciones prácticas. Partiré de algunos casos paradigmáticos procedentes de nuestras prácticas jurídicas en los que asumimos ciertas limitaciones a los derechos fundamentales por consideraciones institucionales. Para empezar, nos resultan familiares algunos supuestos en los que los jueces y tribunales se ven obligados a la hora de tomar decisiones a autorestringirse en su función de protección de los derechos fundamentales en virtud de principios institucionales como el de legalidad o el de deferencia al legislador. Así, por ejemplo, el principio de legalidad en materia tributaria impide que los jueces o tribunales puedan modificar o suprimir tributos, aun cuando estimen que estos pueden ser lesivos para el principio de igualdad tributaria 5 .

4 Cfr. L. LAPORTA, op. cit., 42.

5 De ahí el carácter tan polémico que tuvo la STC 45/1989 que declaró la inconstitucionalidad del sistema de acumulación de rentas entre los integrantes de la unidad familiar por ser incompatible con el principio de igualdad (art. 14 CE). Pese a que la sentencia restringió los efectos del fallo, negando que las liquidaciones efectuadas anteriormente con arreglo a ese sistema declarado inconstitucional pudieran ser revisadas, hubo bastante consenso entre la doctrina en el sentido de que el TC «habría superado los límites del juicio de igualdad, al que se considera ajeno el planteamiento propio del "control de adecuación", al entrar a valorar si la regulación adoptada es o no la más oportuna, olvidando con ello que el principio de proporcionalidad, especialmente en el ámbito económico, solo pone límites extremos a la libertad de apreciación y decisión del legislador, límites que únicamente pueden ser traspasados si sus consideraciones son tan abiertamente falsas que no pueden ofrecer ningún fundamento racional para decisiones legislativas» [Cfr. J. J. ZoRNOZA, «Aspectos constitucionales del régimen de tributación conjunta en el IRPF (Comentario a la STC 45/1989, de 20 de febrero)», en Revista Española de Derecho Constitucional, núm. 27, 1989, 175; J. JIMÉNEZ CAMPO, «La igualdad jurídica como límite frente al legislador», en Revista Española de Derecho Constitucional, núm. 9, 1983,110 y ss.; C. PALAO TABOADA, «La unidad familiar ante el Tribunal Constitucional», en RJE. La Ley, núm. 2.139, 1989, 5, quien afirma sobre la sentencia que «incurre en el defecto de exceder los límites propios de la justicia 
Pero, además, algunas instituciones jurídicas están diseñadas precisamente para hacer prevalecer en determinadas circunstancias consideraciones institucionales sobre derechos fundamentales ${ }^{6}$. Este sería el caso, por ejemplo, de la prisión provisional que limita — entre otras libertades básicas - la libertad de circulación de un individuo en aras a preservar la efectividad del proceso penal. Otro tanto cabría decir de los estados de excepción y sitio, que suspenden la garantía de derechos fundamentales en aras de la preservación de la estabilidad del sistema jurídico como un todo. También la presunción de validez que acompaña a los actos y a las normas jurídicas o el carácter definitivo de las decisiones de última instancia obedecerían a la necesidad de preservar la eficiencia de la maquinaria judicial, aún a costa de sacrificar determinados derechos fundamentales de carácter sustantivo ${ }^{7}$.

Lo que tienen en común principios como el de legalidad o el de deferencia al legislador, instituciones como la prisión provisional, el estado de excepción o sitio, o la cosa juzgada, y presunciones como la de validez de los actos y las normas jurídicas es que todos ellos constituyen ejemplos de mecanismos jurídicos concebidos para la protección de la dimensión institucional del Derecho en caso de conflicto con derechos fundamentales.

No obstante, si abrimos la puerta del razonamiento práctico a razones institucionales, ¿no estaremos contraviniendo un presupuesto fundamental del liberalismo ético, cual es que solo los individuos son agentes morales? Habida cuenta de que si se le atribuye valor a la subsistencia del sistema jurídico o a su eficiencia es porque tales estados de cosas se consideran valiosos para la vida de los sujetos, no me parece que su protección por parte del Derecho tenga en principio porque ser incompatible con el liberalismo ético: la razón por la que el Derecho se blinda frente a consideraciones sustantivas o materiales que él mismo reconoce es garantizar la existencia y la estabilidad de un marco institucional necesario para la supervivencia de los individuos en sociedad.

Ahora bien, a diferencia de lo que sucede con los derechos fundamentales, los bienes o estados de cosas institucionales que se consideran valiosos para la vida de los sujetos no se adscriben a los individuos; no configuran derechos fundamentales que adscribamos a ningún individuo. Por tanto, la dimensión institucional del Derecho impone exigencias que limitan el logro de derechos fundamentales que el propio Derecho trata de realizar. Pero, entonces, ¿cómo puede algo que no es un derecho humano poner límites al ejercicio de derechos fundamentales? ¿No resulta esta idea incompatible con el carácter absoluto de los derechos humanos a la que antes me he referido?

Una forma de sortear esta cuestión consistiría en sostener que la moral no entiende de razones institucionales, sino solo de razones sustantivas: el discurso jurídico impondría exigencias institucionales que son ajenas al discurso moral. Tan pronto como en la deliberación práctica incorporamos consideraciones basadas en razones institucionales abandonamos el territorio del discurso moral e ingresamos en el del discurso

constitucional, invadiendo la esfera de la discrecionalidad legislativa», y H. P. SCHNEIDER, «Jurisdicción constitucional y separación de poderes», en Revista Española de Derecho Constitucional, núm. 5, 1982, 51].

${ }^{6} C f r$. Atienza y Ruiz MANERO, «La dimensión institucional del Derecho y la justificación jurídica», Doxa. Cuadernos de filosofía del Derecho, núm. 24, 127.

7 Sobre la presunción de validez que acompaña a los actos y a las normas jurídicas cfr. A. RóDENAS, Los intersticios del Derecho, Marcial Pons, 2012, p. 61. 
jurídico, con reglas de juego distintas ${ }^{8}$. Pero esta me parece una solución insatisfactoria: puesto que la preservación de la vigencia del sistema jurídico y de cierta eficiencia de su «maquinaria» es necesaria para la consecución de los derechos humanos de los individuos, un discurso moral incapaz de dar cuenta de las limitaciones impuestas por razones institucionales me parece un ejercicio argumentativo perfectamente inútil y gratuito; las razones institucionales me parecen tan necesarias para la arquitectura del razonamiento moral como lo son los derechos humanos. Otra cosa completamente diferente - y de la que no me puedo ocupar aquí- es que para determinar cómo se incardinan en el razonamiento moral tales razones necesitemos acudir a modelos de reflexión del tipo lo segundo mejor.

Ahora bien, asumir que las razones institucionales deben ser tenidas en cuenta en el discurso moral tampoco puede llevarnos al extremo opuesto, que consistiría en mantener que los principios institucionales deben derrotar siempre a los principios sustantivos. Afirmar algo así supondría incurrir en el mismo tipo de error que el positivismo ideológico: si se admite que la preservación de la dimensión institucional del Derecho es un estado de cosas valioso para los individuos, no se ve porque no pueda haber otros bienes o estados de cosas de carácter material o sustantivo cuya preservación deba ser, en ocasiones, más importante; es decir, la salvaguarda de la dimensión institucional del Derecho no puede ser el bien supremo o absoluto.

Por tanto, los principios institucionales forman parte, junto con los derechos fundamentales, del núcleo esencial de las razones justificatorias del Derecho: en abstracto vinculan con idéntica fuerza a los operadores jurídicos; no mantienen una relación ni de prevalencia ni de subordinación respecto de los derechos fundamentales o principios sustantivos. En muchos casos los principios institucionales no tendrán suficiente peso como para desplazar a la solución basada en la garantía de los derechos fundamentales, pero en algunos otros supuestos, sí tendrán peso suficiente como para imponerse sobre los principios sustantivos. Por cierto que asumir una tesis de estas características no tiene porqué llevarnos a suscribir el particularismo ético, siempre y cuando seamos capaces de expresar las relaciones de prioridad entre principios sustantivos e institucionales que afloran a la luz de los casos particulares mediante reglas con una vocación universal: la misma solución para los mismos casos genéricos.

\section{DOS INQUIETUDES GENUINAS}

Puesto que creo haber mostrado la plausibilidad de la tesis de que los principios institucionales prevalecen en algunos casos sobre los principios sustantivos, hay dos inquietudes que se me plantean y que no puedo más que dejar apuntadas aquí.

${ }^{8}$ Este podría ser el punto de vista sostenido por ATIENZA y RuIZ MANERO cuando señalan que «de entrada, el discurso moral ordinario está abierto a todas las razones relevantes, no está sujeto a plazos y la solución de las controversias no depende en él de órgano autoritativo alguno, sino del consenso unánime, por lo demás siempre revisable, de los afectados. Pero es precisamente por estas características por lo que el discurso moral es necesariamente deficitario o insuficiente como método de resolución de los conflictos. Podríamos decir que el carácter institucional del discurso jurídico —entendiendo ahora institucional en el sentido de «regimentado»— es condición necesaria de la superación de los déficits operativos del discurso moral» (Cfr. op. cit., 129). 


\subsection{La deriva comunitarista}

La primera de mis preocupaciones tiene que ver con el inquietante paralelismo entre alguna de las tesis que he suscrito y el postulado central del comunitarismo. Recordemos que el fundamento de los principios institucionales no se encuentra en ningún derecho fundamental o derecho humano; por el contrario, los principios institucionales se fundamentan en el valor singular o cualificado que le atribuimos al Derecho en su conjunto o a determinadas instituciones jurídicas. Esta diferencia en cuanto a su justificación parece sugerir la idea de que los derechos fundamentales y los principios institucionales presentan una morfología diferente: los primeros solo los atribuimos a los individuos; mientras que los segundos los atribuimos a otro tipo de entidades: el Derecho y las instituciones jurídicas.

Pues bien, como es sabido, el comunitarismo defiende que ciertas asociaciones de individuos son portadoras, en sí mismas, de intereses dignos de protección; intereses que pueden coincidir o no con los de los individuos que las componen. En caso de conflicto entre los intereses de la comunidad y los derechos fundamentales de los individuos, el comunitarismo mantiene que los intereses de la comunidad pueden prevalecer respecto de los de los individuos. Así, por ejemplo, puesto que la lengua es un elemento identitario de la comunidad, su protección puede ser impuesta a los sujetos que componen la comunidad con independencia de cuáles sean sus deseos o intereses. Para el comunitarismo menos radical esta prevalencia de los intereses comunitarios se fundamenta en la vital importancia que para el desarrollo del plan de vida de los individuos tiene su pertenencia a una comunidad.

Me parece turbador que este razonamiento guarde cierta similitud con el planteamiento expuesto en el epígrafe anterior, de acuerdo con el cual el juego de los principios institucionales en el razonamiento práctico se funda en la idea de que el Derecho y las instituciones jurídicas son necesarias para el desarrollo de los planes de vida de los individuos, lo que eventualmente puede suponer que sus derechos fundamentales cedan cuando el entramado institucional del Derecho pueda verse seriamente afectado.

No creo que la inquietud que estoy planteando sea imposible de resolver, pero solo puedo dejar aquí apuntado el problema como un reto al que habría que dar respuesta si no se quiere transitar por los populosos jardines del comunitarismo.

\subsection{La deriva consecuencialista}

La imposibilidad de fijar una jerarquía axiológica en abstracto entre principios sustantivos y principios institucionales me suscita una segunda inquietud: inevitablemente el cálculo racional de consecuencias formará parte del razonamiento que, ante cada caso concreto, será necesario llevar a cabo para determinar la prevalencia de uno u otro tipo de principios. El peso de los principios institucionales vendrá dado por la gravedad de los efectos que en cada caso concreto su inaplicación produzca en la dimensión institucional del Derecho que se pretenda proteger por medio de tales principios: la gravedad de tales efectos podría ordenarse en una escala, en uno de cuyos extremos estaría la completa inocuidad para la dimensión institucional del Derecho, y 
en el otro su absoluto colapso, de manera que el orden en la escala de gravedad de los efectos vendrá dado por el cálculo de las consecuencias que en cada caso se sigan para la dimensión institucional del Derecho.

Tan pronto como reparamos en la importancia que el cálculo de consecuencias tiene para resolver los conflictos entre principios sustantivos y principios institucionales, surgen dos dificultades. La primera de ellas es si, al asumir que la resistencia de un derecho fundamental puede ser minada por un principio institucional, no estaremos haciendo una cesión inaceptable al consecuencialismo ético. Reparemos en que son cálculos de consecuencias basados en los efectos que se siguen para las instituciones jurídicas los que van a poner límites a principios sustantivos vinculados a derechos humanos. Cuando introducimos el contexto institucional en el razonamiento práctico, este deja de estar guiado solo por consideraciones morales deontológicas, puesto que abrimos la puerta de entrada en el razonamiento práctico a cálculos consecuencialistas; cálculos que pueden derrotar a las razones deontológicas aportadas por los derechos humanos.

El segundo problema al que voy a referirme es menos trascendental que el anterior, pero no deja de ser preocupante. Es usual achacarle al consecuencialismo ético la ausencia de un método fiable para medir las consecuencias de las acciones. El consecuencialismo institucional al que abocan los principios institucionales tampoco puede sustraerse a esta crítica. ¿Cómo calibrar fielmente la gravedad de las consecuencias que de la inaplicación de un principio institucional se derivan en cada caso concreto para la dimensión institucional del Derecho?

En suma, parece que la plausibilidad de que los principios institucionales puedan prevalecer en algunos casos sobre los principios sustantivos nos lleva a asumir algunos planteamientos que guardan inquietantes similitudes con ciertas tesis del comunitarismo y del consecuencialismo ético. Delimitar qué aspectos de ambas concepciones éticas son asumibles e identificar cuáles son los límites de la incorporación de tales planteamientos requiere una elaboración teórica mucho más sofisticada que la que aquí puedo permitirme, por lo que me he limitado dejar apuntadas ambas inquietudes.

\section{CODA FINAL}

Antes de concluir este trabajo es de estricta justicia destacar que nada de lo que con rigor se ha producido sobre los derechos humanos en las últimas décadas en nuestro ámbito cultural - y tanto menos esta modesta contribución — hubiera sido posible si previamente Paco LAPORTA y Liborio HIERRO no se hubieran aventurado en el selvático territorio de los derechos humanos, abriéndonos, a golpes de afinadas distinciones conceptuales, transitables senderos a los que hemos ido más atrás. 